\title{
Nitrificação e aproveitamento de alguns adubos nitrogenados
}

E. MALAVOLTA, T. COURY, J. D. P. ARZOLLA, H. P. HAAG e M. O. C. DO BRASIL SOBRINHO

E. S. A. "Luiz de Queiroz" U. S. P. - Piracicaba

\section{INDICE}

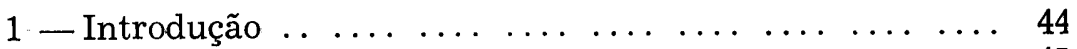

2 - Material e Métodos $\ldots \ldots \ldots \ldots \ldots \ldots \ldots$

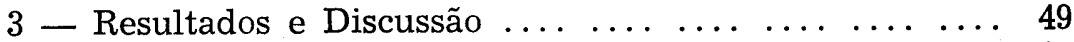

4 - Resumo e Conclusões $\ldots \ldots \ldots \ldots \ldots$

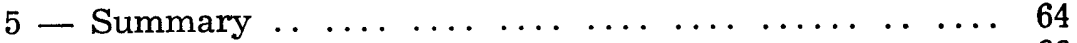

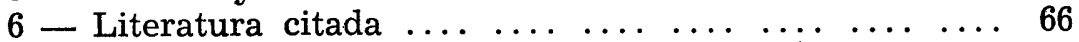

Tese aprovada no VI Congresso Brasileiro de Ciência do Solo Julho de 1957 - Salvador - Bahia

Secção III - Microbiologia do Solo 


\section{INTRODUÇÃO}

E' bem conhecida a grande variabilidade do teor de nitratos no solo arável; há um mínimo na época das chuvas e um máximo na estação sêca. Nestas condições, o teor - variando com a época de amostragem - nem sempre reflete a real riqueza em nitrogênio nítrico e menos ainda a necessidade de adubação nitrogenada.

E' sem dúvida a forma nítrica a "preferida" pela maioria das culturas; daí a importância do fenômeno microbiano de mineralização do nitrogênio que, através da amonização e da nitrificação, transforma o azoto da matéria orgânica em nìratos prontamente assimiláveis.

A microbiologia do solo é ciência que entre nós se acha ainda no nascedouro. Assim poucos trabalhos há sôbre nitrificação dos solos brasileiros.

MALAVOLTA et al. (1955-a) estudaram a nitrificação e aproveitamento de alguns adubos nitrogenados no arenito de Bauru, empregando tortas oleaginosas (amendoim, mamona e algodão), farinhas de sangue e chifre, uréia, calciocianamida e sulfato de amônio.

Empregando a técnica recomendada por HAMENCE (1950) verificaram - após um período de 4 semanas de incubação que, em porcentagem do $\mathrm{N}$ fornecido, os seguintes valores apareciam : uréia - $119,0 \%$; sulfato de amônio - 71,4\%; farinha de sangue $-65,8 \%$; torta de amendoim - 57,4\%; torta de mamona - 29,4\%; torta de algodão - 8,4\% ; farinha de chifre $7,0 \%$; a calciocianamida reduziu a nitrificação do nitrogênio orgânico do solo provàvelmente devido à formação de compostos tóxicos como dicianodiamida, guanidina e guaniluréia. A uréia estimulou a nitrificação do nitrogênio do terreno, daí ? alto índice encontrado. A bôa nitrificação constatada por HAMENCE (1950) em relação à farinha de chifre não foi confirmada no ensaio, possívelmente devido a diversidades no tratamento do material num e noutro caso.

(*) Com ajuda do C. N. Pq. e da Fundação Rockefeller. 
O velho conceito de que a nitrificação era de ação exclusiva de bactérias autotróficas não subsiste. Constatou-se que algumas bactérias heterotróficas e ao que parece um actinomiceto, isolados do solo são capazes de converter a amônia em nitrato. SCHMIDT (1954) comprovou que o Aspergillus flavus obtido a partir do solo efetuou a amonização e a nitrificação completa, isto é :

$\mathrm{N}$ orgânico $\rightarrow \mathrm{N}$ amoniacal $\rightarrow \mathrm{N}$ nitroso $\rightarrow \mathrm{N}$ nítrico

MALAVOLTA et al. (1955-b) trabalhando com várias espécies do gênero Aspergillus verificaram que: a) as linhagens de Aspergillus niger e Aspergillus orizae não nitrificaram; b) as linhagens de Aspergillus flavus experimentadas, ou sejam M4 e IZ 15 nitrificaram bem, embora se comportassem um pouco diferentemente, com menor produção de amônia e nitrito, quando comparadas ao microrganismo usado por SCHMIDT (1954) e c) o Aspergillus wentii demonstrou uma capacidade nitrificadora tão bôa quanto a do Aspergillus flavus.

No presente trabalho procurou-se estudar a nitrificação de diversos adubos azotados em 3 tipos de solo; os seguintes fatores foram considerados: efeito do $\mathrm{CaCO} 3$, micronutrientes e inoculação prévia com $A$. wentii; os resultados da nitrificação foram ainda comparados com ensaios de vegetação.

\section{MATERIAL E MÉTODOS}

2.1. Solos utilizados. Foram empregados nos experimentos 2.3. (laboratório) e 2.4. (vasos) três tipos de solos: terra roxa legítima, terra roxa misturada e terra arenosa (série do Corumbataí) e sòmente terra roxa misturada no ensaio 2.5 (campo). No Quadro I transcrevemos as características químicas dos solos em questão. 


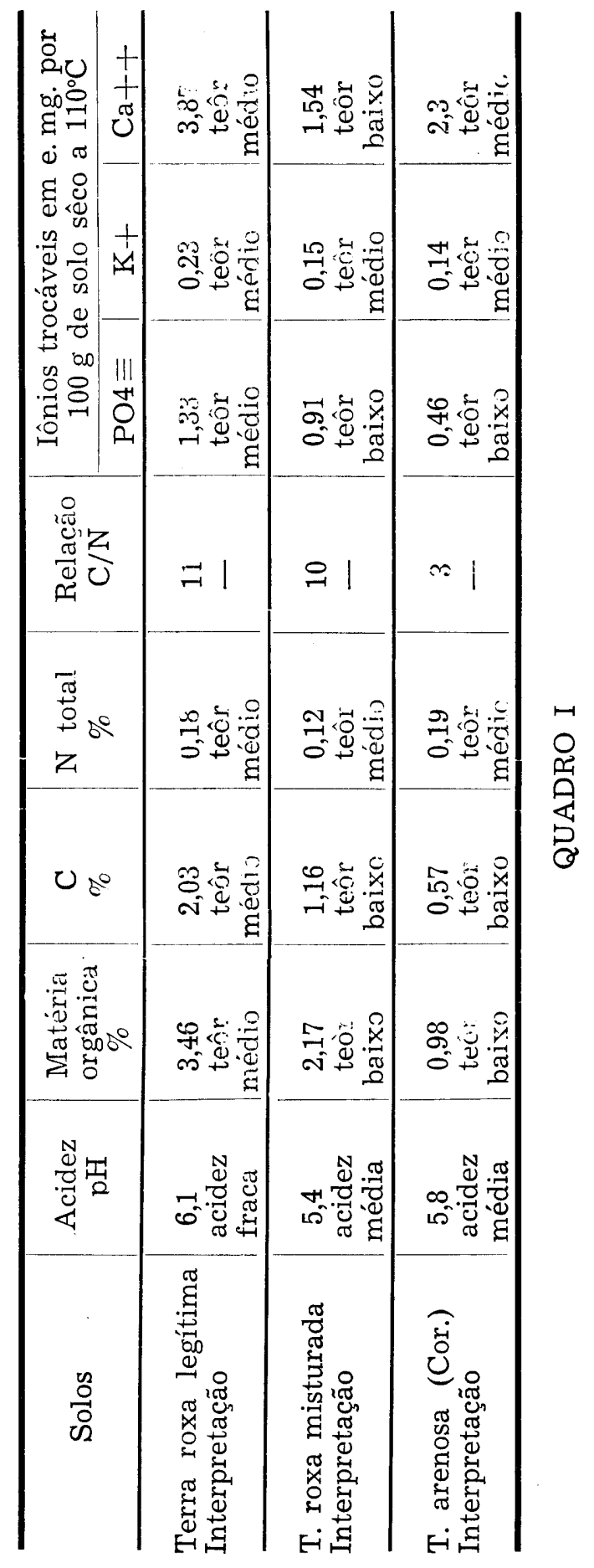


Os métodos analíticos usados foram os seguintes :

a) pH: suspensão de solo 1:1, 18 horas de repouso;

b) matéria orgânica: por uma ligeira modificação ao método de Walkley e Black (MALAVOLTA e COURY, 1954);

c) nitrogênio total: método de Kjeldahl usando-se uma mistura de CuSO4 e KHSO4 como catalisador;

d) fósforo "trocável": por uma modificação à técnica de CATANI (1953) - $4 \mathrm{~g}$ de solo e ' $i 50 \mathrm{ml}$ de H2SO4 0,05N são agitadas em aparelho de Wagner a 40-50 r.p.m. durante meia hora; completa-se a 1 litro, agita-se e filtra-se; numa alíquota de $40 \mathrm{ml}$ dosa-se o fósforo por fotocolorimetria com molibdato de amônio e cloreto estanhoso;

e) potássio "trocável": determinado pelo método de PAIVA NETTO et al. (1947):

f) cálcio trocável: determinado pelo método de PAIVA NETTO et al. (1947).

2.2. Fertilizantes empregados. No Quadro II aparecem as porcentagens de $\mathrm{N}$ total (A.O.A.C. 1945) usados nos ensaios.

\begin{tabular}{lcl}
\hline \multicolumn{1}{c}{ Adubo } & $\mathrm{N}$ total $\%$ & \multicolumn{1}{c}{ Forma do N } \\
\hline Salitre do Chile & 15,5 & Nítrico \\
Sulfato de amônio & 20,5 & Amoniacal \\
Nitrocálcio & 20,2 & 1/2 NO3-e 1/2NH4+ \\
Uréia & 43,3 & Amídico \\
Torta de algodão & 6,1 & Orgânico \\
\hline
\end{tabular}

QUADRO II

2.3. Ensaio de nitrificação. O ensaio de nitrificação foi conduzido de acôrdo com HAMENCE (1950): $100 \mathrm{~g}$ de T.F.S.A. foram postas em cápsulas de porcelana; a seguir misturou-se bem com o solo o adubo nitrogenado (pulverizado e passado através peneira 80 ) numa quantidade correspondente a $7 \mathrm{mg}$ de $\mathrm{N}$ e quando o caso, $100 \mathrm{mg}$ de $\mathrm{CaCO} 3$ droga pura; nos tratamentos com micronutrientes foram colocados $5 \mathrm{ml}$ da solução de HOAGLAND e ARNON (1939) e nos inoculados procedeuse à inoculação com Aspergillus wentii tudo conforme Quadio III. Conhecendo-se a umidade de cada solo e a quantidade de água incorporada através dos micronutrientes e da inoculação, juntou-se água destilada de modo que o teor se elevasse até $20 \%$; manteve-se essa porcentagem durante todo o ensaio, mediante pesagem de cada cápsula e reposição da água evaporada, um dia sim e outro não. As cápsulas foram a seguir cober- 
tas com vidro de relógio e deixadas em ambiente de pouca luz, as abrigo de fortes mudanças de temperatura. Esta, durante o transcorrer do experimento, oscilou entre 26 e $29^{\circ} \mathrm{C}$. Foram coletadas amostras semanalmente (1a., 2a., 3a. e 5a. semanas) nas quais foram feitas determinações do teor de nitritos e nitratos: NO2- foi dosado extraindo-se o solo com ácidıs acético a $10 \%$ (contendo um pouco de zinco em pó) e a seguir tratando-se pelo reativo de Griess. Em outra alíquota do extrato determinou-se $\mathrm{NO} 2-+\mathrm{NO} 3$ - depois de reduzir os últimos com uma mistura de zinco em pó com $\mathrm{MnSO} 4$ e BaSO4.

\begin{tabular}{l|l}
\hline N. & \multicolumn{1}{|c}{ Tratamentos } \\
\hline & \multicolumn{1}{|c}{ Testemunha sem nada } \\
1 & Adubo nitrogenado \\
3 & Adubo N + CaCO3 \\
4 & Adubo N + micronutriente \\
5 & Adubo N + micronutriente $+\mathrm{CaCO} 3$ \\
6 & Adubo N + micronutriente $+\mathrm{CaCO} 3+$ A. wentii \\
\hline
\end{tabular}

QUADRO III

O ensaio portanto, foi feito em 3 tipos de solos diferentes, com 5 adubos nitrogenados e nos 6 tratamentos referidos no Quadro III.

2.4. Ensaio em vasos. No ensaio em vasos com arroz foi seguida a técnica cultural preconizada por MITSCHERLICH (1930). Foram utilizados vasos de Mitscherlich de ferro zincado.

Cada vaso recebeu $6 \mathrm{~kg}$ de T.F.S.A. Os tratamentos e adubação constam do Quadro IV.

Os adubos foram bem misturados com a terra e a irrigação foi feita nos moldes do método de MITSCHERLICH (1930). Procedeu-se à semeadura de 25 sementes de arroz por vaso; desbastou-se após 14 dias deixando 15 plantas por vaso. Nas regas diárias teve-se sempre o cuidado de restituir em primeiro lugar a água percolada no coletor, a qual arrastava evidentemente nitratos. $O$ ensaio foi conduzido em casa de vegetação, ficando os vasos distribuidos ao acaso sôbre vagonetes e a posição dos mesmos modificada de $10 \mathrm{em} 10$ dias. As plantas levadas para fora sòmente no período da manhã. $O$ plantio foi feito em 12-9-56, o desbaste a 26 do mesmo mês e a colheita em março de 1957. 


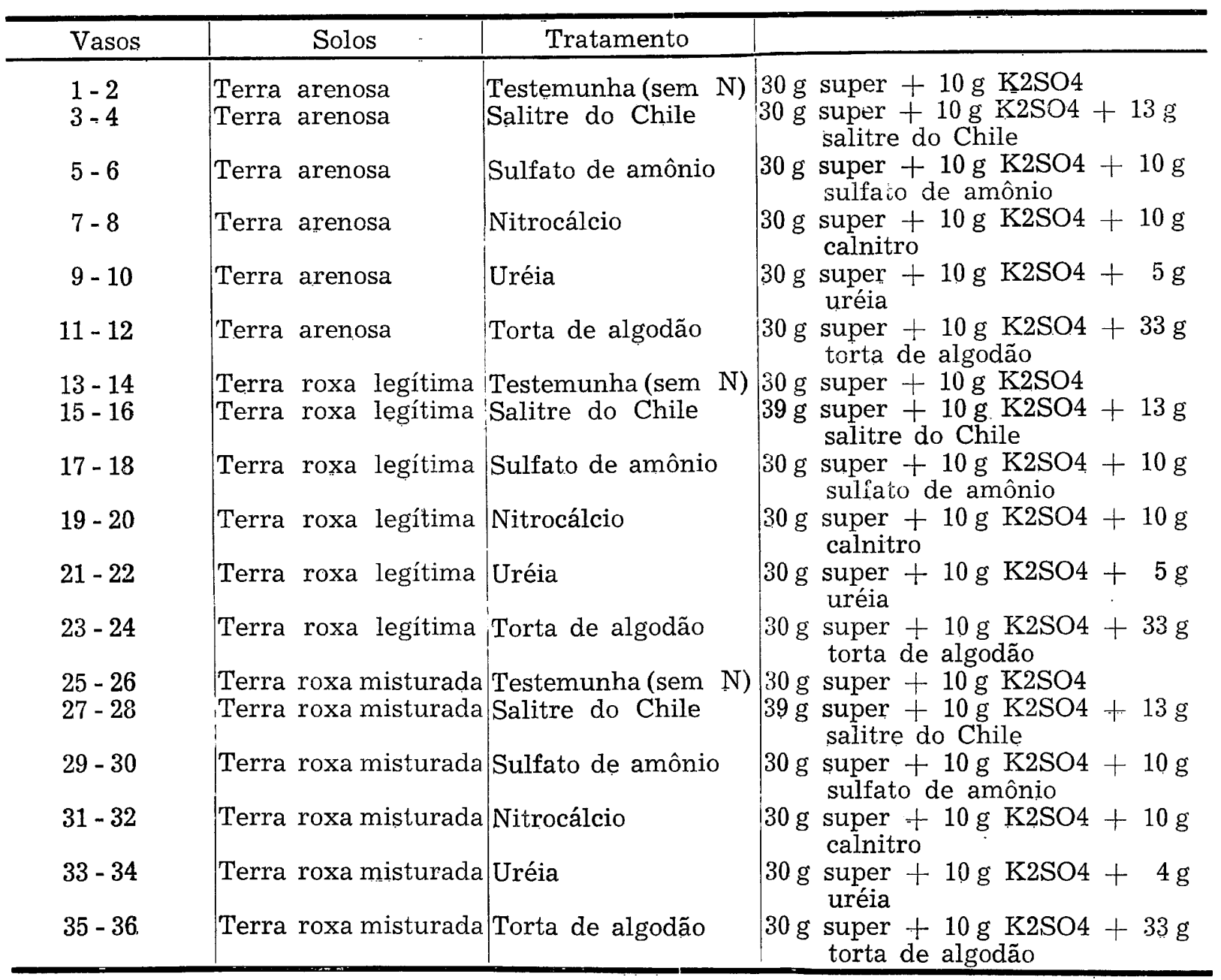

QUADRO IV 
2.5 Ensaio de campo. O experimento de campo foi instalado numa área de terra roxa misturada, com milho cateto, comparando-se os seguintes adubos nitrogenados: salitre do Chile, nitrocálcio, uréia, torta de amendoim e sulfato de amônio. Os tratamentos constam do Quadro V.

\begin{tabular}{c|rcc}
\hline Tratamento & \multicolumn{4}{c}{ Adubação (kg/ha) } \\
\hline & \multicolumn{5}{|c}{$\mathrm{N}-\mathrm{P} 2 \mathrm{O} 5-\mathrm{K} 2 \mathrm{O}$} \\
1 & 0 & 100 & $100($ (sem N) \\
2 & 100 & 100 & $100(\mathrm{~N}$ como salitre do Chile) \\
3 & 100 & 100 & 100 (N como nitrocálcio) \\
4 & 100 & 100 & 100 (N como uréia) \\
5 & 100 & 100 & $100(\mathrm{~N}$ como torta amendoim) \\
6 & 100 & 100 & 100 (N como sulfato de amônio) \\
\hline
\end{tabular}

QUADRO V

O P2O5 foi aplicado na forma de fosforita de Olinda e o $\mathrm{K} 2 \mathrm{O}$ como cloreto de potássio. Quanto ao $\mathrm{N}$, a uréia e a torta de amendoim foram totalmente incorporadas ao solo, por ocasião do plantio; as outras formas ou seja o salitre do Chile, o nitrocálcio e o sulfato de amônio foram aplicadas em 2 vézes, $1 / 3$ da dose na adubação fundamental e o restante em cobertu$\mathrm{ra}$, quando as plantas tinham mais ou menos a altura do joelho de um homem $( \pm 60 \mathrm{~cm})$.

O delineamento escolhido foi o de blocos ao acaso com 4 repetições. Os canteiros mediam 5,0 x 5,0 m, possuindo 6 linhas espaçadas de $1 \mathrm{~m}$. A instalação se deu em 3-11-56 e após o desbaste deixou-se 1 planta em cada $20 \mathrm{~cm}$ de linha. A colheita foi feita em 7 de maio do corrente ano.

\section{RESULTADOS E DISCUSSÃO}

3.1. Ensaio de nitrificação. Os resultados do ensaio de nitrificação se acham resumidos nos Quadros VI, VII e VIII. 
Nitrificação em terra roxa legítima. Os dados referem-se a miligramas de $\mathrm{N}$ nítrico por $100 \mathrm{~g}$ de solo

\begin{tabular}{|c|c|c|c|c|}
\hline Tratamento & 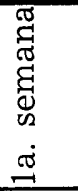 & 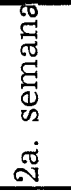 & 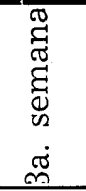 & 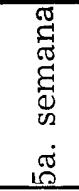 \\
\hline 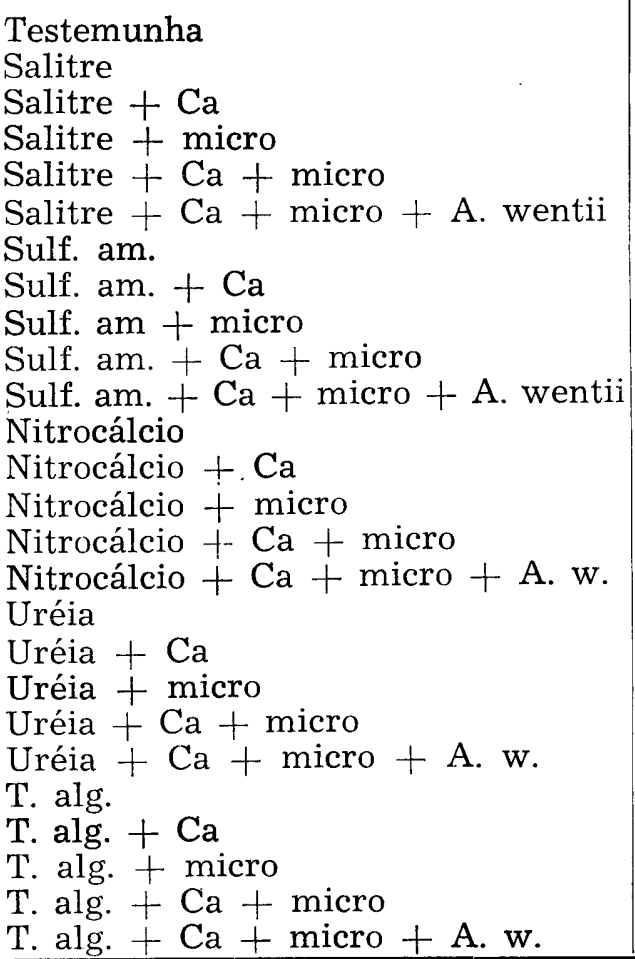 & $\begin{array}{l}1,2 \\
8,0 \\
7,9 \\
7,8 \\
8,1 \\
7,9 \\
3,1 \\
3,0 \\
2,7 \\
2,8 \\
3,1 \\
5,3 \\
4,6 \\
5,6 \\
5,6 \\
5,7 \\
3,3 \\
3,3 \\
3,5 \\
3,2 \\
3,9 \\
3,0 \\
3,8 \\
3,5 \\
3,3 \\
3,9\end{array}$ & $\begin{array}{l}2,5 \\
8,1 \\
8,4 \\
8,0 \\
8,3 \\
8,1 \\
4.1 \\
4,8 \\
3,4 \\
5,0 \\
6,0 \\
5,8 \\
7,7 \\
6,3 \\
7.1 \\
5,3 \\
4.1 \\
7.6 \\
3,2 \\
4,9 \\
7.7 \\
5,1 \\
6,1 \\
6,1 \\
7,5 \\
4.7\end{array}$ & $\begin{array}{r}4,8 \\
11,2 \\
13,3 \\
8,4 \\
9,5 \\
8,8 \\
7,8 \\
7,8 \\
6,8 \\
7,8 \\
7,7 \\
11,7 \\
9,3 \\
7,7 \\
8,2 \\
9,6 \\
7,9 \\
9,1 \\
7,7 \\
7,9 \\
8,2 \\
5,3 \\
9,3 \\
7,0 \\
9,1 \\
8,7\end{array}$ & $\begin{array}{r}5,7 \\
10,5 \\
11,2 \\
12,7 \\
13,8 \\
13,7 \\
10,5 \\
10,3 \\
10,5 \\
11,9 \\
13,1 \\
7,1 \\
9,8 \\
13,0 \\
12,7 \\
12,3 \\
10,5 \\
10,0 \\
12,6 \\
11,2 \\
9,9 \\
9,2 \\
9,1 \\
10,6 \\
9,8 \\
11,9\end{array}$ \\
\hline
\end{tabular}


Nitrificação em terra roxa misturada. Os dados referem-se a miligramas de $\mathrm{N}$ nítrico por $100 \mathrm{~g}$ de solo

\begin{tabular}{|c|c|c|c|c|}
\hline Tratamento & 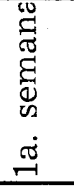 & 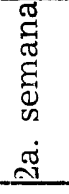 & 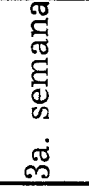 & 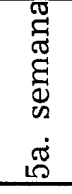 \\
\hline Testemunha & 1,0 & 2,4 & 3,0 & 4,4 \\
\hline Salitre & 7,3 & 8,9 & 9,9 & 11,7 \\
\hline Salitre + Cà & 7,1 & 8,3 & 10,8 & 10,8 \\
\hline Salitre + micro & 8,0 & 9,0 & 10,8 & 11,2 \\
\hline Salitre $+\mathrm{Ca}+$ micro & 7,8 & 9,1 & 10,9 & 12,7 \\
\hline Salitre $+\mathrm{Ca}+$ micro $+\mathrm{A}$. wentii & 7,5 & 9,3 & 11,0 & 12,3 \\
\hline Sulf. am. & $2 ; 5$ & 3,9 & 5,2 & 7,8 \\
\hline Sulf. am. + Ca & 2,7 & 5,6 & 7,0 & 8,7 \\
\hline Sulf. am + micro & 2,8 & 5,1 & 6,7 & 9,2 \\
\hline Sulf. am. $+\mathrm{Ca}+$ micro & 3,2 & 4,6 & 6,8 & 10,9 \\
\hline Sulf. am. $+\mathrm{Ca}+$ micro $+\mathrm{A}$. wenti & 2,8 & 4,6 & 6,6 & 10,6 \\
\hline Nitrocálcio & 4,0 & 5,0 & 7,8 & 10,5 \\
\hline Nitrocálcio + $\mathrm{Ca}$ & 5,0 & 6,0 & 8,0 & 10,0 \\
\hline Nitrocálcio + micro & 4,0 & 6,0 & 7,5 & 12,0 \\
\hline Nitrocálcio $+\mathrm{Ca}+$ micro & 5,0 & 7,4 & 10,1 & 11,2 \\
\hline Nitrocálcio $+\mathrm{Ca}+$ micro $+\mathrm{A} . \mathrm{w}$. & 5,3 & 7,4 & 10,5 & 11,6 \\
\hline Uréia & 2,7 & 4,3 & 6,4 & 8,6 \\
\hline Uréia + $\mathrm{Ca}$ & 2,1 & 5,2 & 7,7 & 9,0 \\
\hline Uréia - micro & 3,1 & 3,5 & 7,4 & 9,0 \\
\hline Uréia $+\mathrm{Ca}+$ micro & 2,5 & 4,8 & 8,4 & 9,5 \\
\hline Uréia $+\mathrm{Ca}+$ micro $+\mathrm{A} . \mathrm{w}$. & 3,5 & 5,4 & 9,1 & 11,9 \\
\hline T. alg. & 2,5 & 3,6 & 5,8 & 7,4 \\
\hline T. alg. $+\mathrm{Ca}$ & 3,0 & 3,8 & 7,6 & 11,9 \\
\hline T. alg. + micro & 2,5 & 4,1 & 5,8 & 9,2 \\
\hline T. alg. $+\mathrm{Ca}+$ micro & 3,1 & 3,8 & 6,5 & 9,9 \\
\hline T. alg. + $\mathrm{Ca}+$ micro + A. w. & 3,1 & 4.1 & 8,4 & 11.4 \\
\hline
\end{tabular}


Nitrificação em terra arenosa. Os dados referem-se a miligramas de $\mathrm{N}$ nítrico por $100 \mathrm{~g}$ de solo

\begin{tabular}{|c|c|c|c|c|}
\hline Tratamento & 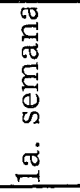 & 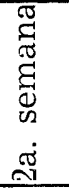 & 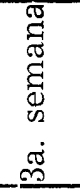 & 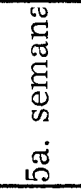 \\
\hline Testemunha & 1,8 & 2,2 & 2,9 & 5,0 \\
\hline Salitre & 7,5 & 9,5 & 10,1 & 11,5 \\
\hline Salitre $+\mathrm{Ca}$ & 7,4 & 9,1 & 9,8 & 11,9 \\
\hline Salitre + micro & 7,4 & 9,1 & 10,7 & 11,5 \\
\hline Salitre $+\mathrm{Ca}+$ micro & 7,5 & 9,1 & 10,7 & 13,0 \\
\hline Salitre $+\mathrm{Ca}+$ micro + A. wentii & 8,4 & 9,0 & 11,6 & 12,0 \\
\hline Sulf. am. & 3,3 & 4,0 & 6,2 & 8,4 \\
\hline Sulf. am. $+\mathrm{Ca}$ & 3,5 & 4,0 & 6,7 & 8,9 \\
\hline Sulf. $a m+$ micro & 4,3 & 4,4 & 7,1 & 9.1 \\
\hline Sulf. am. + $\mathrm{Ca}+$ micro & 4,0 & 4,1 & 6,3 & 11,2 \\
\hline Sulf. am. $+\mathrm{Ca}+$ micro + A. wentii & 3,8 & 4,3 & 6,7 & 11,5 \\
\hline Nitrocálcio & 5,8 & 6,2 & 8,4 & 9,0 \\
\hline Nitrocálcio + Ca & 5,0 & 5,2 & 7,3 & 9,0 \\
\hline Nitrocálcio + micro & 5,6 & $6, \hat{0}$ & 9,5 & 10,5 \\
\hline Nitrocálcio $+\mathrm{Ca}+$ micro & 5,6 & 6,6 & 9,5 & 10,5 \\
\hline Nitrocálcio $+\mathrm{Ca}+$ micro $+\mathrm{A}$. w. & 5,1 & 5,6 & 9,4 & 11,5 \\
\hline Uréia & 2,5 & 3,4 & 6,0 & 8,6 \\
\hline Uréia $+\mathrm{Ca}$ & 2,5 & 4,0 & 4,9 & 8,7 \\
\hline Uréia + micro & 3,0 & 3,2 & 7,0 & 8,8 \\
\hline Uréia $+\mathrm{Ca}+$ micro & 3,3 & 3,6 & 6,2 & 8,8 \\
\hline Uréia + $\mathrm{Ca}+$ micro + A. w. & 3,8 & 4,0 & 7,0 & 10,0 \\
\hline T. alg. & 2,0 & 3,8 & 5,6 & 5,9 \\
\hline T. alg. $+\mathrm{Ca}$ & 3,0 & 2,8 & 6,0 & 9,1 \\
\hline T. alg. + micro & 2,7 & 3,3 & 5,7 & 8,1 \\
\hline T. alg. $+\mathrm{Ca}+$ micro & 3,1 & 3,9 & 5,5 & 8,7 \\
\hline T. alg. $+\mathrm{Ca}+$ micro + A. w. & 3,1 & 3,8 & 7,8 & 10.3 \\
\hline
\end{tabular}

Por falta de tempo não pôde ser feita a análise estatística dos dados de nitrificação. O exame dos quadros VI, VII e VIII permite, porém, sugerir que: na terra roxa legítima o calcário não teve efeito algum na nitrificação e que pode ser devido ao $\mathrm{pH}$ relativamente alto $(6,1)$ de tal solo; os micronutrientes estimularam a oxidação do calnitro, da torta e da uréia; o 
A. wentii ajudou apenas a nitrificação do sulfato de amônio e e da torta; na terra roxa misturada o calcário estimulou a nitrificação do sulfato de amônio e da torta; os micronutrientes auxiliaram a do sulfato de amônio, calnitro e torta; a inoculação mostrou efeito benéfico na oxidação do sulfato de amônio e da torta; no arenito o calcário ajudou a oxidação do calnitro, do sulfato de amônio e da torta ao passo que os micronutrientes beneficiaram aquela dos dois últimos; $A$. wentii estimulou a nitrificação de tcdos. Embora seja difícil fazer uma apreciação global dessas observações não padece dúvida, contudo, que elas deixam perceber alguma deficiência de micronutrientes nos solos estudados e uma relativa pobreza de nitrificadores heterotróficos.

3.2. Ensaio em vasos. Os resultados dêste ensaio se acham expressos nos quadros subsequentes, tanto na produção de palha como de grãos de arroz, com a respectiva análise estatística.

\subsubsection{Terra arenosa.}

\begin{tabular}{lcc}
\hline \multicolumn{1}{c}{ Tratamento } & 1a. repetição & 2a. repetição \\
\hline Testemunha & 20 & 19 \\
Salitre do Chile & 62 & 70 \\
Sulfato de amônio & 63 & 65 \\
Nitrocálcio & 62 & 60 \\
Uréia & 69 & 72 \\
Torta de algodão & 59 & 66 \\
\hline
\end{tabular}

QUADRO IX

Análise da variância

\begin{tabular}{|c|c|c|c|c|c|c|}
\hline 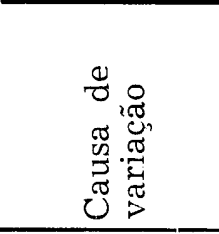 & 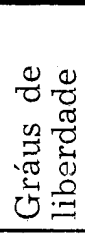 & 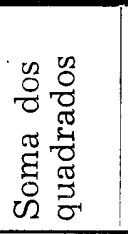 & 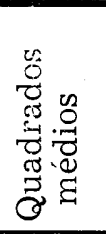 & 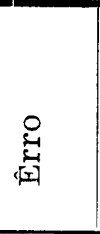 & 范 & 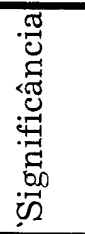 \\
\hline $\begin{array}{l}\text { Tratamentos } \\
\text { Resíduo }\end{array}$ & $\begin{array}{l}5 \\
6\end{array}$ & $\begin{array}{r}3.528 \\
66\end{array}$ & $\begin{array}{r}705,6 \\
11,0\end{array}$ & $\begin{array}{r}26,56 \\
3,32\end{array}$ & 8,0 & *** \\
\hline Total & 11 & 3.594 & - & -1 & -1 & - \\
\hline
\end{tabular}

QUADRO X 
Coeficiente de variação - C. V. $=\frac{100 \mathrm{~s}}{\overline{\mathrm{x}}}=5,8 \%$

Vê-se pelo quadro X que o êrro correspondente a tratamentos foi feito pelo teste teta de BRIEGER (1946), altamente significativo.

Teste de Tukey: com a aplicação dêste teste às médias encontradas (PIMENTEL GOMES, 1954) verificou-se :

Médias por ordem decrescente

\begin{tabular}{l|c}
\hline \multicolumn{1}{c|}{ Tratamento } & $\begin{array}{c}\text { Média de produção } \\
(\mathrm{g})\end{array}$ \\
\hline Uréia & 70,50 \\
Salitre do Chile & 66,00 \\
Sulfato de amônio & 64,00 \\
Nitrocálcio & 62,50 \\
Torta de algodão & 61,00 \\
Testemunha & 19,50 \\
\hline
\end{tabular}

\section{QUADRO XI}

d.m.s. (diferença mínima significativa) pelo teste de Tukey a $5 \%=13,219$ donde,

$$
70,500-13,219=57,281
$$

Constatou-se pelo referido teste que todos os tratamentos nitrogenados diferiram da testemunha ( ferem entre si, ao nível de $5 \%$.

Produção de grãos (g)

\begin{tabular}{l|c|c}
\hline \multicolumn{1}{c|}{ Tratamento } & 1a. Repetição & 2a. Repetição \\
\hline Testemunha & 2,20 & 2,10 \\
Salitre do Chile & 12,50 & 14,00 \\
Sulfato de amônio & 12,10 & 12,30 \\
Nitrocálcio & 12,30 & 12,10 \\
Uréia & 13,50 & 14,10 \\
Torta de algodão & 13,10 & 13,50 \\
\hline
\end{tabular}


Análise da variância

\begin{tabular}{|c|c|c|c|c|c|c|}
\hline 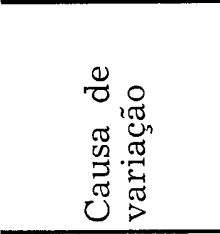 & 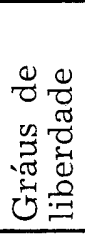 & 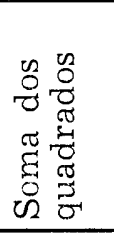 & 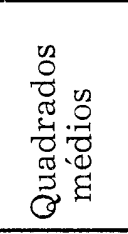 & 密 & 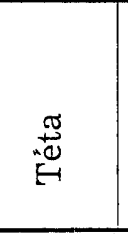 & 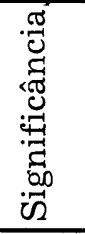 \\
\hline $\begin{array}{l}\text { Tratamentos } \\
\text { Resíduo }\end{array}$ & $\begin{array}{l}5 \\
6\end{array}$ & $\begin{array}{r}198,52 \\
1,43\end{array}$ & $\begin{array}{r}39,700 \\
0,238\end{array}$ & $\begin{array}{l}6,300 \\
0,48\end{array}$ & 12,93 & $* *: k$ \\
\hline Total & 11 & 199.95 & - &.-- & -1 & - \\
\hline
\end{tabular}

\section{QUADRO XIII}

C. V. $=4,4 \%$

O êrro correspondente a tratamentos resultou altamente significativo pelo teste de Brieger.

Teste de Tukey: o confronto entre as médias dos tratamentos tem os seguintes resultados pelo teste de Tukey, ao nível de $5 \%$ :

Médias por ordem decrescente

\begin{tabular}{l|c}
\hline \multicolumn{1}{c|}{ Tratamento } & $\begin{array}{c}\text { Média de produção } \\
(\mathrm{g})\end{array}$ \\
\hline Uréia & 13,80 \\
Torta de algodăo & 13,30 \\
Salitre do Chile & 13,25 \\
Nitrocálcio & 12,20 \\
Sulfato de amônio & 12,20 \\
Testemunha & 2,15 \\
\hline
\end{tabular}

QUADRO XIV

d.m.s. pelo teste de Tukey a $5 \%=1,939$

$$
\begin{aligned}
13,800-1,939 & =11,861 \\
2,150+1,939 & =4,089
\end{aligned}
$$

Igualmente aqui, os tratamentos nitrogenados diferem da testemunha, mas não diferem entre si, na ordem de $5 \%$. 
3.2.2. Terra rôxa legítima.

\begin{tabular}{l|c|c}
\hline \multicolumn{1}{c|}{ Tratamento } & 1a. Repetição & 2a. Repetição \\
\hline Testemunha & 16 & 13 \\
Salitre do Chile & 53 & 51 \\
Sulfato de amônio & 71 & 65 \\
Nitrocálcio & 56 & 63 \\
Uréia & 65 & 65 \\
Torta de algodão & 53 & 60 \\
\hline
\end{tabular}

QUADRO XV

Análise da variância

\begin{tabular}{|c|c|c|c|c|c|c|}
\hline 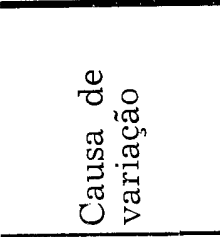 & 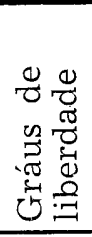 & 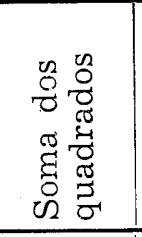 & 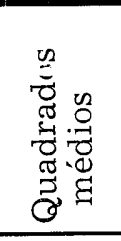 & 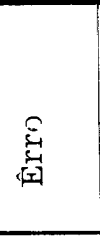 & 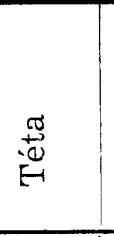 & 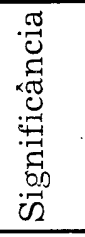 \\
\hline Tratamentos & 5 & $3.811,50$ & 762,30 & 27,61 & 7,80 & $* * *$ \\
\hline Resíduo & 6 & 73,50 & 12,25 & 3,50 & - & - \\
\hline Total & 11 & $3.885,00$ & - & - & -1 & $\therefore$ \\
\hline
\end{tabular}

QUADRO XVI

C. V. $=6,6 \%$

O êrro correspondente a tratamentos deu valor altamente significativo pelo teste teta de Brieger.

Teste de Tukey: confrontados por êste teste os resultados foram os seguintes, ao nível de $5 \%$ :

Médias por ordem decrescente

\begin{tabular}{l|c}
\hline \multicolumn{1}{c|}{ Tratamento } & $\begin{array}{c}\text { Média de produção } \\
(\mathrm{g})\end{array}$ \\
\hline Sulfato de amônio & 68,00 \\
Uréia & 65,00 \\
Nitrocálcio & 59,50 \\
Torta de algodão & 56,60 \\
Salitre do Chile & 52,00 \\
Testemunha & 14,50 \\
\hline
\end{tabular}


d.m.s. pelo teste de Tukey a $5 \%=13,967$

$$
68,000-13,967=54.033
$$

Todos os tratamentos foram nítidamente superiores à testemunha e o sulfato de amônio foi significativamente superior, ao nível de $5 \%$, ao salitre do Chile.

\begin{tabular}{l|c|c}
\hline \multicolumn{1}{c|}{ Tratamento } & 1a. Repetição & 2a. Repetição \\
\hline Testemunha & 1,90 & 3,10 \\
Salitre do Chile & 10,90 & 11,20 \\
Sulfato de amôni & 15,00 & 13,90 \\
Nitrocálcio & 11,30 & 12,10 \\
Uréia . & 12,30 & 13,10 \\
Torta de algodão & 10,90 & 12,10 \\
\hline
\end{tabular}

\section{QUADRO XVIII}

\section{Análise da variância}

\begin{tabular}{|c|c|c|c|c|c|c|}
\hline 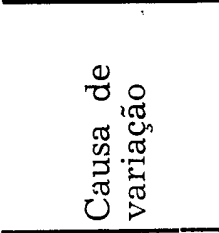 & 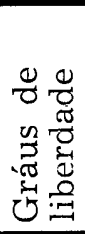 & 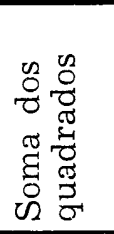 & 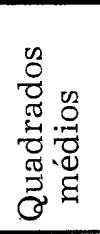 & 总 & 焉 & 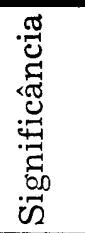 \\
\hline $\begin{array}{l}\text { Tratamentos } \\
\text { Resíduo }\end{array}$ & $\begin{array}{l}5 \\
6\end{array}$ & $\begin{array}{r}174,07 \\
2,70\end{array}$ & $\begin{array}{r}34,81 \\
0,45\end{array}$ & $\begin{array}{l}5,90 \\
0.67\end{array}$ & 8,80 & $* * *$ \\
\hline Total & 11 & 176,80 & - & - & -1 & $\ldots$ \\
\hline
\end{tabular}

QUADRO XIX

C. V. $=6,3 \%$

O êrro correspondente a tratamentos foi significativo pelo teste téta de Brieger.

Teste de Tukey: pelo teste de Tukey a $5 \%$ foram obtidos os seguintes resultados entre as médias dos tratamentos: 
Anais da E. S. A. "Luiz de Queiroz"

\begin{tabular}{l|c}
\hline \multicolumn{1}{c|}{ Tratamento } & $\begin{array}{r}\text { Média de produção } \\
(\mathrm{g})\end{array}$ \\
\hline & \\
Sulfato de amônio & 14,45 \\
Uréia & 12,70 \\
Nitrocálcio & 11,90 \\
Torta de algodão & 11,50 \\
Salitre do Chile & 11,05 \\
Testemunha & 2,50 \\
\hline
\end{tabular}

\section{QUADRO XX}

d.m.s. a $5 \%$ pelo teste de Tukey $=2,667$

$$
14,450-2,667=11,783
$$

Todos os fertilizantes nitrogenados diferem da testemunha. Entre os nitrogenados, o sulfato de amônio sobrepujou os demais, salvo a uréia; não obstante esta não diferiu significativamente dos outros.

3.2.3. Terra roxa misturada.

\begin{tabular}{l|c|c}
\hline \multicolumn{1}{c|}{ Tratamento } & 1a. Repetição & 2a. Repetiçãa \\
\hline Testemunha & 11,00 & \\
Salitre do Chile & 35,00 & 15,00 \\
Sulfato de amônio & 54,00 & 45,00 \\
Nitrocálcio & 52,00 & 46,00 \\
Uréia & 50,00 & 52,00 \\
Torta de algodão & 45,00 & 42,00 \\
& & 41,00 \\
\hline
\end{tabular}

QUADRO XXI 
Análise da variância

\begin{tabular}{|c|c|c|c|c|c|c|}
\hline 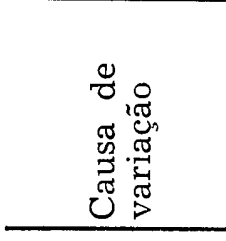 & 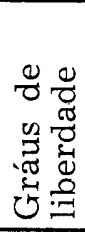 & 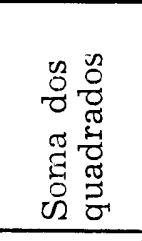 & 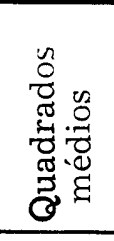 & 密 & 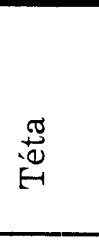 & 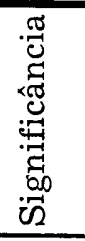 \\
\hline $\begin{array}{l}\text { Tratamentos } \\
\text { Resíduo }\end{array}$ & $\begin{array}{l}5 \\
6 \\
\end{array}$ & $\begin{array}{r}2.030,67 \\
130,00 \\
\end{array}$ & $\begin{array}{r}406,13 \\
21,67\end{array}$ & $\begin{array}{r}20,15 \\
4,63\end{array}$ & $\underline{4,33}$ & ** \\
\hline Total & 11 & 2.160 .67 & - & $\ldots$ & - & $\ldots$ \\
\hline
\end{tabular}

\section{QUADRO XXII}

C. $\mathrm{V} .=11 \%$

O êrro correspondente a tratamentos deu significativo pelo teste teta.

Teste de Tukey: por êste teste, ao nível de $5 \%$, os resultados são :

Médias por ordem decrescente

\begin{tabular}{l|c}
\hline \multicolumn{1}{c|}{ Tratamento } & $\begin{array}{c}\text { Média de produção } \\
(\mathrm{g})\end{array}$ \\
\hline Nitrocálcio & 52,00 \\
Sulfato de amônio & 50,00 \\
Uréia & 46,00 \\
Torta de algodão & 43,00 \\
Salitre do Chile & 40,00 \\
Testemunha & 13,00 \\
\hline
\end{tabular}

QUADRO XXIII

$$
\text { d.m.s. a } 5 \%=18,514
$$$$
52,000-18,514=33,486
$$

Sucedeu, a exemplo dos anteriores, diferença entre todos os nitrogenados confrontados com a testemunha, embora sem diferirem entre si, pelo teste de Tukey a $5 \%$. 
Produção de grãos (g)

\begin{tabular}{l|c|c}
\hline \multicolumn{1}{c|}{ Tratamento } & 1a. Repetição & 2a. Repetição \\
\hline Testemunha & 2,1 & 2,2 \\
Salitre do Chile & 8,9 & 7,5 \\
Sulfato de amônio & 10,3 & 9,8 \\
Nitrocálcio & 10,1 & 10,2 \\
Uréia & 10,1 & 8,9 \\
Torta de aigodão & 9,0 & 8,1 \\
\hline
\end{tabular}

\section{QUADRO XXIV}

Análise da variância

\begin{tabular}{|c|c|c|c|c|c|c|}
\hline 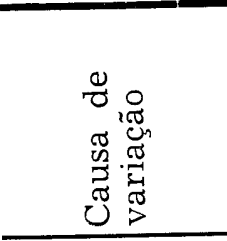 & 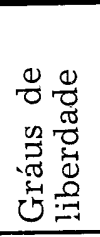 & 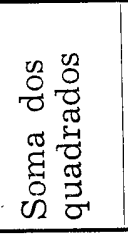 & 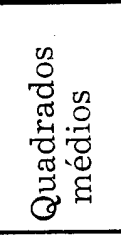 & 莺 & 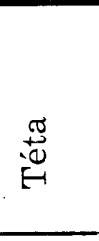 & 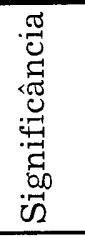 \\
\hline $\begin{array}{l}\text { Tratamentos } \\
\text { Resíduo }\end{array}$ & $\begin{array}{l}5 \\
6\end{array}$ & $\begin{array}{r}91,16 \\
2,24\end{array}$ & $\begin{array}{r}18,230 \\
0,373\end{array}$ & $\begin{array}{l}4,270 \\
0,611\end{array}$ & 6,99 & **:: \\
\hline Total & 11 & 93.40 & - & - & - & -. \\
\hline
\end{tabular}

QUADRO XXV

C. V. $=3,8 \%$

O êrro correspondente a tratamentos deu significativo pelo teste teta.

Teste de Tukey: foram os seguintes, os resultados dos tratamentos pelo teste de Tukey, na ordem de 5\%:

\begin{tabular}{l|c}
\multicolumn{2}{c}{ Médias por ordem decrescente } \\
\hline \multicolumn{1}{c}{ Tratamento } & $\begin{array}{c}\text { Média de produção } \\
(\mathrm{g})\end{array}$ \\
\hline Nitrocálcio & 10,15 \\
Sulfato de amônio & 10,05 \\
Uréia & 9,50 \\
Torta de algodão & 8,55 \\
Salitre do Chile & 8,20 \\
Testemunha & 2,15 \\
\hline
\end{tabular}




$$
\begin{gathered}
\text { d.m.s. a } 5 \%=2,433 \\
10,150-2,433=7,710
\end{gathered}
$$

Os tratamentos nitrogenados diferem todos da testemunha, mas não entre si, na ordem de $5 \%$ pelo ieste de Tukey.

3.3. Ensaios de campo. Os resultados de campo, com milho cateto se acham expressos nos Quadros XXVII e XXVIII i a seguir a análise da variância no Quadro XXIX e produção em ordem decrescente no Quadro XXX.

Produção de milho em quilos

\begin{tabular}{l|c|c|c|c}
\hline \multicolumn{1}{c|}{ Tratamento } & Bloco A & Bloco D & Bloco C & Bloco D \\
\hline Testemunha & 6,4 & 5,1 & 5,5 & 6,1 \\
Salitre do Chile & 9,0 & 8,1 & 8,5 & 7,9 \\
Nitrocálcio & 8,3 & 7,7 & 7,9 & 7,4 \\
Uréia & 7,3 & 6,9 & 7,7 & 6,1 \\
Torta de amendoim & 7,9 & 6,3 & 6,5 & 6,3 \\
Sulfato de amônio & 8,9 & 7,9 & 8,5 & 8,0 \\
\hline
\end{tabular}

QUADRO XXVII

Médias de produção

\begin{tabular}{l|c|c|c}
\hline \multicolumn{1}{c|}{ Tratamento } & $25 \mathrm{~m}^{2} \quad(\mathrm{~kg})$ & Hectare $(\mathrm{kg})$ & $\begin{array}{c}\text { Alque re } \\
\text { (sacos de } \mathbf{6 0 k g}\end{array}$ \\
\hline Testemunha & 5,775 & 2,308 & 93 \\
Salitre do Chile & 8,375 & 3,348 & 135 \\
Nitrocálcio & 7,825 & 3,128 & 126 \\
Uréia & 7,000 & 2,800 & 113 \\
Torta de amendoim & 6,750 & 2,700 & 109 \\
Sulfato de amônio & 8,325 & 3,328 & 134 \\
\hline
\end{tabular}


Análise de variância

\begin{tabular}{|c|c|c|c|c|c|c|}
\hline 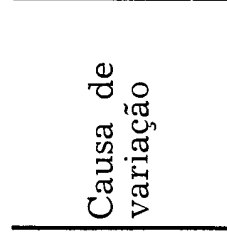 & 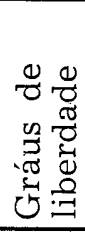 & 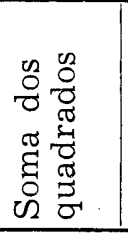 & 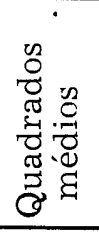 & . & 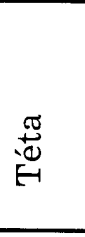 & 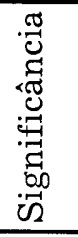 \\
\hline Blocos & 3 & 3,94 & 1.313 & - & - & $\ldots$ \\
\hline Tratamentos & 5 & 20.76 & 4,152 & 2,030 & 4,01 & $* * *$ \\
\hline Resíduo & 0 & 2,06 & 0,257 & 0,506 & - & $\ldots$ \\
\hline Total & 23 & 26,76 & - & - & - & - \\
\hline
\end{tabular}

\section{QUADRO XXIX}

$$
\text { C. V. } \frac{100 \mathrm{~s}}{\mathrm{x}}=7,34 \%
$$

O efeito de tratamento foi altamente significativo pelo teste teta de Brieger. Para apreciar melhor as diferenças entre os trabalhos foi usado o teste de Tukey. Pelo referido teste a d.m.s. a $5 \%$ é igual a 1,308 .

Médias de produção por ordem decrescente

\begin{tabular}{l|c}
\hline \multicolumn{1}{c|}{ Tratamentos } & Médias (kg) \\
\hline Salitre do Chile & 8,375 \\
Sulfato de amônio & 8,325 \\
Nitrocálcio & 7,825 \\
Uréia & 7,000 \\
Torta de amendoim & 6,750 \\
Testemunha & 5,775 \\
\hline
\end{tabular}

\section{QUADRO XXX}

Sendo a d.m.s. igual a 1,308 temos :

8,375 (produção maior) $-1,308=7,067$

5,775 (produção menor) $+1,308=7,083$ 
Nestas condições, sòmente os 3 primeir s tratamentos do Quadro XXX ou sejam o salitre do Chile, o sulfato de amônio e o nitrocálcio respectivamente diferem da testemunha. Contudo não diferem entre si no nível de $5 \%$. bos.

3.4. Relação entre nitrificação e aproveitamento dos adu-

Terra Roxa legítima: no confronto da nitrificação com os resultados do ensaio em vasos, verificou-se que a) a produção de palha e grãos de arroz decresceu na seguinte ordem: suliato de amônio, uréia, nitrocálcio e torta de algodão; b) houve igual sequência decrescente quanto à nitrificação salvo o nitrocálcio que se classificou em último lugar.

Terra roxa misturada: comparando-se os dados da nitrificação com os resultados do ensaio em vasos e do experimento de campo pode-se constatar que a) a nitrificação, em ordem decrescente foi : nitrocálcio, uréia, sulfato de amônio e torta de algodão; b) a ordem de produção de palha e grãos de arroz foi a mesma com apenas troca de posição entre a uréia e o sulfato de amônio; c) nas condições de campo a produção de mitho em função dos diversos adubos variou na mesma direção aue os dados de nitrificação, excetuando-se -o caso do sulfato de amônio que, embora tendo sido pouco nitrificado, garantiu boa produção. As formas orgânicas de uréia e torta tiveram as mais baixas produções, superiores apenas à testemunha.

Terra arenosa: neste tipo de solo a ordem decrescente de nitrificação foi a que se segue: nitrocálcio, uréia, sulfato de amônio e torta. Entretanto, se confrontado com a produçãc de palha de arroz, o nitrocálcio passa para a 3a. posição na ordem decrescente, permanecendo a torta sempre no último lugar. Já na produção em grãos processou-se uma reviravolta com a seguinte ordem de produção decrescente: uréia, torta, nitrocálcio e sulfato de amônio. Note-se que, enquanto nas terras roxas legítimas e misturada o sulfato de amônio prevaleceu na me.lhor produção de grãos, na arennsa foi a mais baixa. Também como era de se esperar, de um modo geral nos 3 solos a torta oleaginosa nitrificou mal e deu produção baixa.

\section{RESUMO E CONCLUSÕES}

A nitrificação do sulfato de amônio, do nitrocálcio, da uréia e da torta de algodão foi estudada em três tipos de solos a saber: terra roxa legítima, terra roxa misturada e arenito Corumbataí. Procurou-se verificar também o efeito dos seguintes tratamentos: calcário, micronutrientes e inoculação com 
Aspergillus wentii, um fungo nitrificador. Os resultados analíticos mostram que : na terra roxa legítima o calcário não teve efeito algum na nitrificação enquanto os micronutrientes estimularam a oxidação do calnitro, da torta e da uréia; o $A$. wentii ajudou apenas a nitrificação do sulfato de amônio e da torta; esta última em todos os tratamentos deu origem a uma quantidade menor de nitratos; na terra roxa misturada todos os adubos, em função dos tratamentos apresentaram uma mineralização máxima; o calcário ajudou a nitrificação do sulfato de amônio e da torta; os micronutrientes auxiliaram a do sulfato de amônio, calnitro e torta; a inoculação mostrou efeito benéfico na oxidação do sulfato de amônio e da torta; no arenito a intensidade de nitrificação foi a mesma para os diversos adubos ensaiados; o calcário auxiliou a nitrifícação do ca!nitro, do sulfato de amônio e da torta ao passo que os micronu.irientes beneficiaram aquela dos dois últimos apenas; a inoculação com $A$. wentii estimulou a nitrificação de todos.

Para verificar o aproveitamento dos adubos mencionados foram feitos dois ensaios, um em vasos com arroz usando-se os três tipos de solos e outro no campo com milho, apenas na terra roxa misturada. No arenito Corumbataí não houve diferહnça significativa na produção de palha e grãos de arroz para nenhum dos adubos empregados, a saber: os mesmos cuja nitrificação se estudou e mais o salitre do Chile incluido no experimento como padrão; houve muito pouca concordância entre os dados de nitrificação e o mérito relativo dos adubos avaliado pelos dados de produção. Na terra roxa legítima o sulfato de amônio venceu, de modo geral, a competição; houve um bom paralelismo enire niirificação no laboratório e colheiia n:s vasos.

Em terra roxa misturada no que diz respeito ao ensaio em vasos o comportamento dos diferentes adubos seguiu a mesma tendência evidenciada no arenito Corumbataí; os dados de nitrificação concordam râzò̀velmente com a preduçãa rbłida n s vas s. No ensaio de campo (milho) houve superioridade do salitre do Chile, sulfato de amônio e nitrocálcio (e vivalentes entre si) em reiação à uréia e à toria que não diferiram da testemunha.

\section{SUMMARY}

The rate of nitrificaition of several nitrogenous fertilizers (ammonium sulfate, nitrc-chalk, ureia, and cottonseed meal) was siudied in ihree soils, namely, "terra roxa legítima", a red soil derived from basalt, "terra roxa misturada", a soil al- 
su derived fr $\mathrm{m}$ basalt but with a higher proportion of sand. and "arenito Corumbatai", a sandy soil. The effects of the following treatments on nitrification were considered: addition of limestone of micronutrients ( $\mathrm{Fe}, \mathrm{Cu}, \mathrm{Zn}, \mathrm{Mn}$, and $\mathrm{Mo}$ ), and inoculation with a suspension of spores of Aspergillus wentii, a heterotrophic nitrifier. The results showed that: in "terra roxa legítima" limestone had no influence on the nitrification rate, whereas the micronutrients estimulated the oxidation of nitrc-chalk, cottonseed meal and urea; inoculation with $A$. wentii helped only the nitrification of ammonium sulfate and of the cottonseed meal; the latter, in all the treatments employed gave use to a smaller amount of nitrates; in "terra roxa misiurada", all the fertilizers depending upon the treatments they were subjected to, presented maximum values for nitrification; limestone estimulated the oxidation of ammonium sulfate as well as the mineralization of the cottonseed meal; the addition of micronutrients helped the nitrification of all the fertilizers, except that of urea; inoculation showed a benefical influence on the nitrification of ammonium sulfate and cottonseed meal; in "arenito de Corumbatai", the amounts of nitrates produced was roughly the same for all the fertilizers investigated; limestone estimulated the nitrification of nitro-chalk, ammonium sulfate and cottonseed meal whilst the addition of micronutrients benefited only the latter two; the inoculation with $A$. wentii helped the oxidation of all the fertilizers.

In order to study the availability of the various fertilizers above discussed, two plant growing experiments were carried cut, one in pots, using the three soil types and another one in the field, with "terra roxa misturada". In "arenito de Corum. batai" there was no significant difference in the yield both of straw and rice grains for none of the fertilizers: Chilean nitrate of soda was used as a control; no marked agreement could be detected between the data concerning nitrification and the yield results. In "terra roxa legítima", ammonium sulfate won the competition and there was a good parallelism between nitrification and yield.

In "terra roxa misturada", there was no statistical difference among the various fertilizers; the agreement between nitrification and yields was reasonable. In the field (corn), Chilean nitrate, ammonium sulfate and nitro-chalk were clearly beter than urea and cottonseed meal which did not differ from the minus nitrogen plots. 


\section{LITERATURA CITADA}

A. O. A. C., 1945 - Official and tentative methods of analysis, sixth ed., Washington, 4, D.C.

BRIEGER, F. G., 1946 - Limites unilaterais e bilaterais na análise estatística. Bragantia 6 (10): 479-545.

CATANI, R. A., 1953 - Comunicação particular.

HAMENCE, J. H., 1950 - A method for the determination of the relative availability of .nitrogen in nitrogenous fertilizers. Jour. Sci. Food and Agric. 193: 92-96.

HOAGLAND, D. R. and D. I. ARNON, 1939 - The water culture method for growing plants without soil. Univ. of California Agr. Exp. Sta. (Berkeley, Calif.) Circ. 347.

MALAVOLTA, E. e T. COURY, 1954 - Práticas de Química Agrícola. E. S. A. "Luiz de Queiroz" (Piracicaba). Mimeografado.

MALAVOLTA, E., T. COURY, D. PELLEGRINO e H. P. HAAG, 1955-a - Nitrificação e aproveitamento de alguns adubos nitrogenados no arenito de Bauru. Rev. Agr. XXX (4-5-6) : 133-151.

MALAVOLTA, E., R. CAMARGO e H. P. HAAG, 1955-b Nota sôbre a nitrificação por fungos do solo. Bol. n. 13 I. Zimotécnico (Piracicaba).

MITSCHERLICH, E. A., 1930 - Die Bestimmung des Dungerbedurfnisses des Bodens, Dritte Auflage, Paul Parey, Berlin.

PAIVA NETTO, J. E., R. A. CATANI, M. S. QUEIROZ e A. KUPPER, 1950 - Contribuição ao estudo dos métodos analíticos e de extração para a caracterização química dos so. los do Eseado de S. Paulo. An. 1a. Reu. Bras. Ciência do Solo (Rio de Janeiro) : 79-109.

PIMENTEL GOMES, F., 1954 - A comparação entre médias de tratamentos na análise da variância. An. Esc. Sup. Agr. “L. Queiroz”, U. S. P. (Piracicaba) 11: 1-12.

SCHMIDT, E. L., 1954 - Nitrate formation by a soil fungus. Science 119: 187-189. 